\title{
Refining the Concept of Political Will: A Gender Perspective
}

By Elena Doldor, Deirdre Anderson and Susan Vinnicombe

Accepted for publication in British Journal of Management

\begin{abstract}
While politics is known to be prevalent at managerial levels, there is currently little insight into what drives managers to engage in organizational politics and whether there are gender differences in this respect. In the current study we explore the concept of political will by using a qualitative approach based on 14 semi-structured interviews with managers (5 men and 9 women) in a global semi-conductor company. We identify key dimensions of managerial political will consisting of three attitudinal ambivalences: functional, ethical and emotional. We also examine gender differences along these dimensions and discuss managers' political will in the context of a masculine organizational setting. We conclude by discussing the theoretical and practical implications of the findings and further research directions.
\end{abstract}

Key words: organizational politics, political will, gender, women managers 


\section{INTRODUCTION}

There has been a persistent call for more politically aware and politically skilled managers (Ammenter et al., 2002; Hall et al., 2004; Hartley et al., 2007), as well as clear evidence that political skill facilitates managerial effectiveness (Buchanan, 2008). The increased interest in the political dimension of managerial roles has so far translated into research tackling political behaviour and political skill. However, Mintzberg (1983) argued that effective political actors must display both political will and political skill. Little scholarly attention has been paid so far to what drives engagement in politics. Addressing this research gap, this paper aims first to explore the concept of political will from the perspective of managers as political actors, thereby investigating organizational politics at a micro-level.

In addition to an insufficient grasp of political will, research in the field has largely ignored the role of gender in understanding managers' involvement in politics. Women's absence among the highest corporate ranks remains widely documented in the UK and abroad (Vinnicombe et al., 2008; Sealy et al., 2009). One of the explanations accounting for the persistent gender gap in corporate leadership lies with gender differences in influencing behaviours in general (Guadagno and Cialdini, 2007) and particularly with women's alleged reluctance to engage in organizational politics (Perrewe and Nelson, 2004). Given the scant existing research on this topic, the causes, manifestations and consequences of women's lack of political appetite remain relatively unclear. The second aim of this paper is to address this research gap by exploring gender differences in the expression of political will among male and female managers. 
The paper is structured in four sections. Firstly, we position the current study within extant literature, drawing on two relatively distinct bodies of literature: organizational politics and women leaders. The second section explicates the qualitative exploratory methodology of the study. The third section presents the empirical findings, mapping out the conceptual dimensions of political will and exploring its gender aspects. Finally we discuss the findings and their theoretical and practical implications.

\section{Organizational politics in managerial roles}

Although organizational politics have a bad reputation among academics and practitioners (Buchanan and Badham, 2007), politics in organizational leadership are increasingly conceptualized as constructive management of shared meaning rather than as manipulative use of power (Ammenter et al., 2002). Organizational politics refer to informal influence attempts enacted to defend individual or group interests that may overlap or not with broader organizational interests, taking place in conditions of uncertainty or ambiguity (Pfeffer, 1992; Mintzberg, 1983). Reviews of the literature in this field (Doldor and Singh, 2008; Ferris et al., 2002) indicate that the political dimension of managerial roles has been explored through two main lenses: political behaviours and political skill. The repertoire of political behaviours or tactics identified ranges from pro-social (coalitions, friendliness, networking, self-promotion, mentoring) to anti-social (attacking or blaming others, engaging in conflict, exploiting others, coercion, blackmail) (Buchanan and Badham, 2007; Ralston et al., 1994; Zanzi et al., 1991). In addition, political skill has been found to be a strong predictor of managerial performance (Douglas and Ammeter, 2004; Semadar et al., 2006).

However, Minztberg (1993) suggested that both political will and political skill underpin effective political action. While political skill is the ability to execute 
political behaviours competently, political will refers to individual's motivation to engage in such behaviours. Ferris et al. (1994) argued that a political model of leadership requires a better understanding of political will as a behavioural antecedent, defining it as 'the propensity to behave politically'. Politics are known to be an integral part of managerial roles (Madison et al., 1980) yet it is unclear what drives skilled managerial involvement in politics. We believe that research into the political dimension of managerial roles would benefit from further conceptualization and empirical investigation into political will.

Political will has been so far conceptualized and measured by focusing on dispositional antecedents of political behaviour. Defined as 'tendencies to respond to situations, or classes of situations in a particular, predetermined manner' (House et al., 1996), dispositions encompass personality characteristics, need states, attitudes, preferences, and motives. Seeking predictors of political behaviour, scholars have particularly focused on personality characteristics such as need for power, need for achievement, intrinsic motivation, Machiavellianism or active influence, all found to be positively related to political behaviours (Porter et al., 1981; Treadway et al., 2005). We suggest that a more complete conceptualization of the propensity to behave politically can be achieved through the examination of individuals' specific attitudes towards organizational politics and towards engaging in politics.

While personality traits are fairly stable individual dispositions across time and context (Adams et al., 2008), attitudes are shaped by both individual and contextual factors (Maio and Haddock, 2010), thus being more fluctuant. Given the contextual nature of politics, we suggest that managerial political action needs to be understood by taking into account both individual preferences and the contextual factors shaping them. The controversial nature of politics and the pervasiveness of politics in 
managerial roles make it important to examine how managers' actual political behaviours are informed by the way they construe organizational politics and the role of politics in their own job. Therefore, this study adopts a more focused definition of political will by contending that attitudes towards politics and engaging in politics are a closer indicator of managerial political will than personality proxies.

\section{Gender and organizational politics}

Whilst much has been written on the absence of women from leadership ranks in organizations, there has been little exploration of the impact of organizational politics on gender inequalities in access to leadership. Limited research on the topic raised the issue of women’s distaste for politics (Arroba and James, 1988). Mann (1995) argued that women fail to recognize the importance of politics because they are not sufficiently familiarized with the informal mechanisms of power such as networking, power coalitions, and 'old boys' clubs'. Yet some have suggested that women's career progression could be facilitated by political skill (Perrewe and Nelson, 2004; White et al., 1997). In a study of high profile executive women in US corporations, Mainiero (1994) found that while taking on leadership roles women go through a process of political maturation, progressing from naïve to astute politicians through a gradual refinement of their political skill. While Mainiero's study suggests that political skill is essential for progress within executive ranks, it leaves unexplored the beliefs and views about politics that underpinned executive women's political maturation, thus neglecting political will.

Davey (2008) noticed that female business graduates tend to construe politics as irrational, instrumental and competitive and therefore more consistent with masculine behavioural patterns. Although aware of the importance of politics in securing power, 
these women remained conflicted between wanting to have more power and rejecting the political games necessary to obtain it. However, these studies have been limited by their all female samples, as well as by a neglect of context in understanding women's political appetite. Buchanan and Badham (2007) indicate that women often choose not to engage in certain political tactics, particularly in aggressive ones. These studies seem to suggest that lack of political awareness or political skill alone does not fully account for women's non-involvement in politics, especially at more senior levels. Exploring gender differences in political will may provide more meaningful answers as to what may underpin different political engagement of male and female managers. Therefore, in setting out to refine the concept of political will and to examine it at an individual level and from a gender perspective, the current study aims to contribute first to the literature on organizational politics and second to the literature on gender in management.

\section{METHOD}

\section{Qualitative approach}

In terms of methodological fit (Edmondson and McManus, 2007), an exploratory approach was deemed adequate given the relatively low development of current theory and research on the topics addressed: political will and the gender differences involved. Adopting a critical realist perspective, we employed qualitative methods to examine managers' attitudes towards engaging in politics, aiming to map out the conceptual boundaries of political will (Neuman, 2006). The methodological choice also needs to be understood in the context of a broader critical realist (CR) philosophical perspective. The epistemic aim of CR is to infer deeper structural mechanisms which explain observable events of the social world and to examine how 
these generative mechanisms apply in specific contexts (Danermark et al., 2002). Aligned with the research gap stated above and with the philosophical and methodological stance described here, we remained mindful of the factors, mechanisms and conditions which shaped managers' willingness to engage in politics. While CR does not entail commitment to a specific methodology, we considered particularly valuable for the current study the ability of qualitative approaches to elicit contextual and rich data about political settings and processes, thus concurring with Buchanan’s (1999) call for more qualitative inquiry into politics.

\section{Organization and participants}

The size and nature of the sample allows for theoretical as opposed to numerical generalization; theoretical generalization is consistent with the goal of developing a new construct or contributing to a nascent field of research (Flick, 2004). This exploratory study used a sample of 14 managers, consisting of 5 men and 9 women, with ages ranging from 27 to 62 . All participants had product and people management responsibilities at middle and upper management levels, holding positions across an array of functions (HR, finance, sales, PR) in one of the world's largest semiconductor companies (Semcom). Both men and women with various levels of experience were interviewed, in order to elicit different views and experiences and thus provide rich conceptual material. Participants were selected by consultation with the point of contact in the company. Operating in a male-dominated industry, Semcom had approximately 20\% women in managerial roles. The company was active in addressing gender aspects at a corporate level, with various diversity policies and initiatives (women's networks, executive development programmes). Informal conversations with the point of contact portrayed a fairly direct, non-hierarchical and participative organizational culture, valuing a process-driven approach. 


\section{Data collection and analysis}

Semi-structured interviews were chosen as a method of data collection because they are flexible enough to facilitate exploration of under-examined phenomena or constructs (Oppenheim, 2001). The approach to data collection and analysis can be broadly mapped onto Kvale's (1996) stages of interviewing. Thematizing and designing refer to the alignment between the research question addressed and interview protocol. The key interview questions referred to beliefs, emotions, and behaviours related to personal involvement in politics. These are classes of evaluative responses considered essential in inferring attitudes (Eagly \& Chaiken, 1993). Probing questions were used flexibly to explore issues salient to participants. The interviews were conducted either by phone or face to face (at Semcom's UK offices) and lasted one hour on average.

Permission was given (with only one exception) for interviews to be recorded and transcribed. Following transcription, interviews were coded using a template analysis approach (King, 2007) supported by NVivo software (version 8.0). Template analysis blends a structured conceptual approach with a looser, emergent interpretation. The initial template was based on a priori codes taken from the main interview questions and included, 'beliefs', 'emotions' and 'behaviours' related to politics. The data was then coded against this provisional template with new codes being added and the a priori codes progressively redefined. Constant consultation among the authors enabled re-clustering and re-defining of nodes and the template was thus updated as nodes become more abstract and interpretive rather than purely descriptive (Miles and Huberman, 1994). For instance, beliefs about political engagement were most often discussed by considering potential beneficial and negative outcomes, as well as ethical aspects of political engagement; these two themes were clustered under the 
broader node called 'beliefs' and were categorized under new nodes called 'functional' and 'ethical'. Informed by CR, we aimed to consider and go beyond individual subjective meanings, by detecting common patterns in managers' expressed political will and formulating explanations about the generative mechanisms accounting for these patterns.

Verifying and reporting required addressing quality criteria relevant to the chosen methodology. Patton (2002) argued that the trustworthiness of qualitative studies hinges on credibility, transferability, dependability and confirmability. Credibility is closely linked to the ability of conducting rigorous fieldwork and thorough analysis in qualitative inquiry. To ensure authenticity and plausibility of individual accounts (Miles and Huberman, 1994), we framed the interview in a nonjudgmental way, giving firm reassurance about the confidentiality of the results. We also probed carefully during the interview, remaining particularly vigilant to contradictory statements. Lincoln and Guba (1986) draw attention to the notion of transferability, which means that the relevance of patterns identified and explanations proposed in different settings needs to be judged by examining the similarity between contexts. This will be addressed in the discussion. Finally, qualitative research must allow for external audit by being rigorous and transparent in the process of data collection and analysis, thus enabling others to judge its dependability and confirmability (Lincoln and Guba, 1986). This was achieved by providing a careful account of the steps undertaken in this study. 


\section{FINDINGS}

\section{Dimensions of political will and gender}

Willingness to engage in politics was conveyed by a series of core beliefs and emotional reactions emerging from the participants' accounts. Three attitudinal ambivalences summed up the array of contradictory feelings and beliefs expressed with regards to politics, thus mapping out the salient dimensions of managerial political will: functional, ethical and emotional. Namely, organizational politics were perceived to be at the same time (1) functional and dysfunctional, (2) ethical and unethical and (3) pleasant and stressful. These themes ran across the entire sample, irrespective of age and functional background. While we are distinguishing among these dimensions for the purpose of conceptual clarity, they were inevitably intertwined in individual accounts. These dimensions conveyed political will for all participants; however the experiences pertaining to them were to some extent different for male and female managers. Women's accounts suggested that a masculine organizational culture left an indelible mark on their political journeys. In contrast, men did not see gender relevant in understanding managers' experiences with politics. Aligned with a CR perspective (Danermark et al., 2002; New, 2004), gender was relevant at two levels when analyzing and reporting the findings: first as sex differences between the responses of male and female managers, second as social practices around sex differences which create gender orders. We use the terms 'gender differences' and 'gendered practices' to refer to these two. To facilitate reporting, participants were given pseudonyms. 


\section{Between functional and dysfunctional: functional ambivalence}

Judgements about the functional aspects of politics were related to the foreseen effects of engaging in politics. Such engagement was often described as a ubiquitous and unavoidable part of organizational life and of managerial roles. Due to their increased complexity and relational nature, managerial roles seemed to have shaped participants' political will by raising awareness of the necessity to engage in politics in order to accomplish business goals not only by relying on technical expertise, but by being able to gain people’s support. Engagement in politics was also associated with reputational gains or risks, as Heather's comment indicates.

We're all judged all the time... people are looking at how you handle things. And if you don't manage the politics very well, that's seen as being a very junior thing, oh she can't handle the office politics. I think those kind of things, if you choose to go in and tackle them, then if you don't do them well, then they're typically very public amongst the management team.... it's seen as more of a negative thing than if you fail on something else, because it's seen as this big business acumen if you can deal with it, and if you can't then it's also seen as a big failure. (Heather)

Amongst the most frequently mentioned benefits of engaging in politics were coalition building, securing resources, increased efficiency, reputational gains and career progression. The main downsides of politics were related to unnecessary and manipulative game-playing, pursuing individual goals at the expense of collective gains, creating conflicts, and thus engendering discomfort and frustration amongst employees. All participants discussed both benefits and downsides of engaging in politics, thus conveying functional ambivalence. They also commented that taking on 
managerial roles made them more cognizant of the benefits of engaging in politics, as well as the costs of opting out, hinting to the changes in their understanding of these functional aspects. However, while both male and female participants were aware of the necessity to engage in politics in one way or another, the underpinning functional rationale was to some extent gender-specific. Male participants discussed the functional benefits of engaging in politics either for career benefits or from a taskfocused perspective. Adrian's quote typifies this last point.

[Politics] is an important part of our job because it's not only about delivering the right product at the right time to customers, but also in giving customers the right level of support. So supporting customer's decisions, supporting internal decisions in order to support those customers. So in my opinion it is quite important. And it's also important to influence the organisation in the way that, for example the level of headcount that's assigned to different parts of the organisation is right. (...) In all those areas there is some politics in order to achieve results. (Adrian)

This confirms that engagement in politics is seen as necessary and leading to both functional and dysfunctional outcomes, at both an individual and organizational level (Buchanan, 2008; Drory, 1993; Ferris and Kacmar, 1992; Gandz and Murray, 1980; Madison et al., 1980). While most female participants were fully aware of the business-related benefits of political engagement, they also perceived political engagement as a way to navigate a covert masculine organizational culture. This culture was essentially portrayed by experiences and meanings that are typically described as masculine and ascribed to men (Alvesson, 1988). When discussing work experiences that triggered willingness to engage in politics, most female participants mentioned gendered incidents such as old boys’ networks, golf club socializing, 
tokenism, or gender stereotypes in the workplace. A typical example is Alice's story about seeing male colleagues getting promoted before her because they had been more strategic in using impression-management, a political behaviour which women are often uncomfortable displaying (Singh et al., 2002).

I had someone in my team who was not doing much more than me, I would even say that I was quite proud of my results while I thought his were less important. And to me he was playing politics, like spending a lot of time inside the building, discussing with managers, while I was with my customers. Then there was some training with some EMEA $^{1}$ managers and he was there to discuss with them, even if to me it was nothing to say, just to get known... And usually he was working at the questions that he should be asking if the opportunity came to speak to them... And then at the end of the year, he got promoted and I was not and I thought it was not something really fair. And I discussed that with my manager, and he said look, you are not visible enough, you do the right stuff, but if I'm talking to the EMEA organization, they don't know much about you. They might know the results, but who has been accomplishing that? (Alice)

Feeling that she lost out because of not playing a political game defined in masculine terms, Alice seems to collude with this masculine practice by resigning herself to being savvier about impression management in light of the perceived functional benefits. While her account suggests positive attitudes on the functional dimension of political will, it also conveys negative attitudes on the emotional dimension, chiefly expressed as discomfort.

\footnotetext{
${ }^{1}$ EMEA = Europe Middle East and Africa
} 
So I have to admit that even if I would be more comfortable having the results speak for themselves, and maybe having my manager promoting the work that I've been doing and then me only concentrating on the goal that I have to accomplish, it's true that if I take the time to think about politics and the way that I present the result, the way I present the issue that we have, and to whom I communicate that, it can be very powerful and it helps me save some time later on, and some energy. (Alice)

The excerpt suggests that Alice's willingness to engage in impression management perpetuates the status quo by leaving this political gendering process unchallenged. However, she then expands on how her managerial role allows her to play the game on masculine terms, legitimized by the need to promote her team, as opposed to herself. This conveys a tension between the perceived need to perform the game in masculine terms, and the adherence to normative expectations of women as communal and selfless (Heilman, 2001).

For me now it's easier thinking about the fact that I'm not alone, I have a team to promote and it's easier for me to say I would be promoting the work of my team rather than I would be promoting myself. (Alice)

Another reference to the intertwined nature of gender and political practices is Irene's account about the challenge of establishing credibility in what she called a 'macho culture’ with ‘a rugby team mentality’. Irene recalls being assigned trivial roles in meeting (drafting the agenda, picking the dinner menu) as a sign of resistance to any meaningful contribution from her part, as a peer manager. She clearly labels these gendered politics as 'strong biases towards gender', noting that 
it took her years to be perceived as an equal by her male colleagues. In contrast to Alice’s approach, Irene actually overtly challenges this masculine culture.

I think that over the past years we've been able to address some of these issues. And I know a few months ago I openly brought up the boys club. I don’t think there are many companies where you can go to the senior manager and just say 'You know, there's a boys' club and you guys are criticized to be involved in it'. And I think that was a really good exercise, I mean the feedback was very positive. So, I think the open door policy, as we call it within [Semcom], can be used to deal with this kind of topic. (Irene)

In doing so, she draws on values embraced by the organization; the 'open door policy', or the ability to freely communicate across hierarchical ranks, was often quoted by participants as emblematic of Semcom's non-hierarchical working environment. Irene's strategy of challenging political practices which are informal and gendered by appealing to formal and gender-neutral corporate values can arguably be seen as a political act in itself. Her comments also suggest a positive shift in Semcom's take on gender diversity, a point raised by several female participants. Thus, while women's political experiences may have been coloured by a masculine culture, their willingness to engage in politics can actually be driven by an attempt to resist, reform or survive this culture. Illustrating this, Amy describes how socializing around typically male activities can constitute a barrier for women's access to the informal reins of power.

I think there is an issue that men tend to group together socially... and play golf. And a lot of decisions are made really when they're doing things like that. 
So it is quite challenging as a woman to break through sometimes and influence their thinking. (Amy)

She then describes at length the strategies she used to cope with this masculine culture, ranging from learning to play golf and joining the 'guys', to downplaying her expertise at golf and asking for unnecessary help on the golf course to establish rapport with her male colleagues in a non-threatening way. Drawing on Gherardi's notion of ceremonial and remedial gender work (1994), Amy's political tactic can be seen as a perfunctory way to defer to an established gender order thorough mimicked ceremonial work. At the same time, it is a sign of resistance and a subtle form of remedial work. Unlike Irene, Amy does not overtly challenge masculine cultural practices. In fact, she seemingly 'does gender’ (Mark and Zimmerman, 1987) by engaging in behaviours consistent with the conventional understanding of being a woman, yet remains very aware how playing this ceremonial ritual eventually enables her to achieve business goals as a manager, an outcome ultimately disruptive to ongoing gender inequalities.

While all participants explored how political engagement could enable or obstruct the achievement of business objectives and pointed out benefits and downsides of engaging in politics, some of the most negative attitudes pertaining to the functional dimension of political will were expressed by women.

No, I really don’t like it. I think it's wasting time, energy... You're losing faith as well, it's just a lack of faith and time. (Emma)

This is perhaps not surprising, given that female participants discussed at length how engagement in politics allows them to navigate a masculine organizational culture, in addition to simply enabling them to pursue managerial objectives. 


\section{Between right and wrong: ethical ambivalence}

A second attitudinal dimension related to politics had to do with ethical issues, often framed in terms of 'right' and 'wrong' or 'fair' and 'unfair'. Confirming prior findings (Buchanan 2008; Kumar and Thibodeaux, 1990; Cavanagh et al., 1981), this dimension suggests that politics and political engagement remain fraught with ethical concerns. Ethical judgments were generally linked to the purpose pursued when engaging in politics. All participants disapproved of politics employed for individual purposes only and most of them considered it legitimate to engage in politics for the overall good of the team or the company. Few participants acknowledged the fact that individual and collective goals are not necessarily mutually exclusive.

I guess I'm not so opposed to that as long as people are driving a business agenda for using it. I guess that is fair, because I don’t have ethical issues using office politics as long as it helps the group or the overall company or our sales and marketing group to win, to get ahead, then that is ok for me. The more it goes to the individual win, then I'm a little bit more sceptical or I try to stay away from it. (Harry)

The fact that politics were seen as legitimate when related to task accomplishment is perhaps linked to the outcome-oriented work ethic of the organization. Commenting on the working style characterizing Semcom's ethos, one manager described its employees as 'doers'. So engagement in politics was not perceived as ethically problematic as long as it led to functional organizational benefits; this illustrates the interdependence between the functional and the ethical dimensions of political will, as shaped by organizational setting. While the political pursuit of personal gain was unacceptable to most participants, male participants often had 
patterns of response such as the one below, acknowledging the ambivalence of politics and analysing the 'good' and the 'bad', but concluding by focusing on the constructive aspects when defining their own terms of engagement.

Politics has two faces: a nice one and an ugly one. (...) There is good and bad. The good is influencing people to create a win-win situation or to create benefit for the company and there's negative politics where the ego is in the foreground and people try to influence for their personal benefit. But I really believe in win-win situations. (Andrew)

The notion of 'win-win' was used by several participants to describe what was perceived to be a legitimate approach to politics: one aiming to reconcile diverse interests among stakeholders, as opposed to a zero-sum conception of political action. This resonates with an increasing interest among scholars for 'constructive politics' (Butcher and Clarke, 2006) or 'positive political action’ (Kurchner-Hawkins and Miller, 2006). In contrast to this sanctioned facet of politics, a few female managers were very vocal in condemning political engagement motivated by self interest. As other studies suggested (Buchanan, 2008), a few women were also concerned about the victimizing effect politics might have on others.

When I say I'm getting mad, I think I'm putting myself in the position realizing that maybe other people can't detect people doing politics or maybe people cannot react to other people making politics, you know, people not being able to defend themselves. (...) And you have people just using politics as a weapon to put people down. So you know, I'm just getting really aggressive and defensive because I'm thinking about that as well. (Emma) 
Emma goes on to explain how these ethical concerns have shaped her style of engaging in politics toward an interventionist, corrective approach.

Probably ten years ago I would have said okay, whatever, I don't care. But now I'm fighting with it, I'm fighting against it. (...) I can now deal with it in a different way, whereby I make people aware that what they do is wrong. (Emma)

Emma's comment suggests that political will is not necessarily synonymous with 'playing the game' as defined by the status quo. Instead, political will may entail a drive to challenge political practices perceived as unethical or even to opt out. Between the 'right' and 'wrong' attitudinal extremes there was a middle point of ethical relativism, corresponding to participants who made contextual judgements about the moral nature of politics. For instance, Adrian describes how his attitude towards politics evolved from an overall negative perception to contextual moral judgements:

At the early stage of my career when I didn’t understand how [politics] works. I was seeing it as a negative thing, something that I would like to avoid because it was not clear for me how to use it. (...) And then I developed an understanding of the organisation. I was getting to the perspective that this is really without any positive or negative aspect itself, it is based on how you are using it. (...) And some people have very negative opinion about politics because politics is influencing people outside of the normal influencing path. But there is nothing wrong with that as long as you're not using it for achieving something which is not good. In my opinion politics is like energy or money - it depends where you put it. You either have good results or bad 
results. So politics itself cannot be good or bad. It really depends how you're using it. (Adrian)

This gradual resolution of ethical dilemmas posed by politics and contextual understanding of ethical aspects related to politics appeared to stem from a certain political maturation, alluded to by both male and female managers.

\section{Between playfulness and cautiousness: emotional ambivalence}

A third ambivalent attitudinal dimension emerged at the emotional level, when participants mentioned what they enjoyed and disliked about politics. From the repertoire of ambivalent emotions two extremes stood out: women's cautiousness (encompassing frustration, discomfort vigilance, wariness) and men's playfulness (encompassing excitement, interest, comfort). Using a game-playing metaphor, Isaac describes as exhilarating the experience of engaging in politics.

Business is like a big game. We are all big children. So to have a good game you have to have good rules; politics is like non-official rules (...) So for me, to play this game could be funny, exciting, and the thing I love most is to understand the psychology of others. Politics is just a psychology game... (Isaac)

Commenting on what shaped his attitudes toward politics, he singles out his manager as a key source of mentoring and role modelling in the political arena. In contrast, Irene uses vivid language to express her distaste for politics, which she describes as obstructive and stressful. Her expression of political will entails resisting 'the game' behaviourally, and a negative experience emotionally. 
I think it’s an obstacle. I don’t do politics, I can’t do politics, I never could do politics. It makes me cringe. (...) The only thing I guess I would enjoy is stopping it. (Irene)

Underpinning Irene's resistance is an understanding of politics as a male enterprise and as antithetical to 'work'. In describing politics as 'a man's thing', the undercurrent in her account is an assumed incompatibility between political action and female values.

It goes back to nurturing, to childhood. I was always brought up 'You'll be rewarded for the work you do’. Typical woman, I know, but when I have to do politics, or stay in politics or join, nope, no, not for me. I think actually for years politics has been associated, I don't know, for me, it's been men and white shirts and ties. It's been a man's thing. (Irene)

This account is at some level similar to Alice's story in the previous section, about her realization that she needs to engage in impression management as much as her male peers in order to reap the same career benefits. While Alice appeared resigned to performing this mainstream masculine political tactic, despite being uncomfortable with it, Irene staunchly resists it and condemns other women engaging in politics. Echoing another female participants' comment that 'women don't like to be seen as doing politics', Irene endorses a double standard in judging male and female political actors.

Maybe it disturbs me more because it's the same gender as myself. I just don’t like, I just did not like women who do politics. (... ) You know, the 
example I would give you - it's okay to see a guy drunk, but I think it's horrid to see a drunk woman. (Irene)

It must be stressed that Irene's and Isaac's accounts represent extreme (negative and positive) examples of the subjective experiences expressed across the sample. Most male and female participants highlighted both emotionally rewarding and emotionally demanding aspects of political engagement. For instance, both Heather and Adrian appreciate being able to understand the informal power web and various agendas at stake, and to identify and influence key decision-makers.

In general I think it's very interesting how we can influence the result at the end. So from that perspective I like to understand what's going on and who's making the decision and how to influence the people making the decision. What kind of arguments will work best and so on. So that's the interesting part and that's what I like. (Adrian)

I like the challenge of it. And I think, once you learn to identify who are the game players, it's a great learning experience to watch them in action. So, again, you know, once you've realised that actually, some of the guys who look like they don't care are actually the best ones, watching their style of business or their style of interaction, they're pretty impressive. (Heather)

Just like their male counterparts, several women expressed emotional neutrality and acceptance of politics as an unavoidable organizational reality.

I don't really think about it one way or the other because I just see it as inevitable, as part of everyday working life. (Sarah) 
Once affected by it, you obviously have to play along, either drive it forward or defend. I guess I'm comfortable with it, somewhat comfortable. (Harry)

These women acknowledged that politics are often construed as masculine. However unlike Irene, they were at ease with the idea of engaging in it, albeit it required navigating double standards and developing skills which did not fit normative definitions of femininity.

I just think sometimes the ability to influence is often seen as quite a male strength. (...) it's something that women probably think they're not good at but with a bit of coaching it turns out that they can be. (Amy)

Some women were even savvy in navigating structural inequalities constraining political engagement. Heather for example believes that pervasive gender prejudice leads others to underestimate or ignore female managers as viable political players. She construes this as an advantage, challenging the accepted thesis that tokenism raises visibility and engenders disadvantage (Kanter, 1977).

I think men and women can play politics equally well. Where women are winning more at the moment is there are less of us in management. A lot of the men are still quite arrogant to the fact that men are better than women. That is the harsh reality, so they don't see us doing it. (Heather)

Although currently at ease with the idea of political engagement and aware of its gendered nature, these women commented that the emotional experience of engaging in politics had changed over time and with experience, paralleling the refinement of their political skill. Interestingly, overall male participants did not see gender as relevant in any way to understanding willingness to engage in politics. 
I, personally, couldn't say that there would be a difference, at least not with what I've witnessed. I might just not have the right antennas to pick up, but if I look around at the male, female colleagues that I have I do see similarities. It might be just because they're all [Semcom] brain-washed, that could easily be the case, that we all have a pretty similar way of working. I mean, we all have the same training classes, we all have the same code of conduct. (Harry)

\section{DISCUSSION AND CONCLUSION}

This study aimed to contribute to the literature on organizational politics by providing a clearer conceptualization of political will and to the literature on gender in management by examining political will from a gender perspective. Aiming to expand current understanding of what drives managers to engage in politics, we sought to conceptually refine and empirically substantiate the concept of political will. Initially introduced by Mintzberg (1983), the notion of political will holds the promise of providing a more holistic understanding of managerial political action (Ammenter et al., 2002; Ferris et al., 2002; Vredenburg and Maurer, 1984). Yet to date, political will has been conceptualized and measured from a dispositional angle, chiefly by resorting to personality traits which convey general inclinations to exercise influence or desire to acquire power (Adams et al., 2008; Treadway et al., 2005). In the current study, we proposed that political will can be better understood by focusing on managerial attitudes toward politics and engagement in politics, as opposed to focusing on managers' generic proclivity for power and influence. Findings revealed core attitudinal dimensions relevant to understanding managers' willingness to engage in politics, as informed by their own views and experiences about organizational politics and political engagement: functional, ethical and emotional. Essentially, these 
dimensions bring a novel insight into the core concerns guiding managers' involvement in politics: Is it useful? Is it ethical? How do I feel about it? Indicating a widespread attitudinal ambivalence, politics were described by participants as being simultaneously functional and dysfunctional (functional ambivalence), ethical and unethical (ethical ambivalence) and pleasant and stressful (emotional ambivalence). This demonstrates that politics remains a controversial topic which triggers strong, polarized attitudes not only in public perception (Buchanan and Badham, 2007), but also among managers.

The comparative analysis of the views expressed by male and female managers revealed the significance of the findings in mapping out three dimensions of managerial political will in general and unpacking gender differences along these dimensions. While all three dimensions of political will were relevant to understanding what drives political engagement for both male and female managers, there were gender differences in the experiences pertaining to these dimensions. The most extreme negative attitudes along the three dimensions were expressed by women.

The functional dimension of political will emerged when participants commented on the benefits and downsides of political engagement. Confirming previous studies (Buchanan, 2008; Buchanan, 1999; Madison et al., 1980), findings indicated that managers perceived politics as both a threat and an opportunity in achieving individual and organizational objectives. In addition to these generic functional considerations, female managers perceived organizational politics not only as an expression of a masculine culture but also as a way to navigate it. Many of the political situations mentioned by women ('old boys' club', gender differences in impression management) were of a gendered nature. Women's strategies of coping 
with the embedded masculinity of political practices ranged from overt resistance to reluctant acceptance. Several women conceded engaging in masculine political practices for the sake of functional benefits (increased personal visibility, lucrative relationships and coalitions). A few women employed shrewd political strategies as a way of coping with or disrupting a masculine culture, illustrating how political action blurs the boundaries between ceremonial and remedial gender work (Gherardi, 1998). For women, political engagement was not only about doing managerial work, but also about 'doing gender' in that it represented practices and processes stemming from and perpetuating gender inequalities (Acker, 1990; West and Zimmerman, 1987). Thus, while this study reinforced previous findings about managers' perceptions regarding the usefulness of politics, it also showed that female managers ascertain the functionality of politics by considering how political engagement enables them to navigate the gendered dynamics of the workplace.

The second dimension of political will is the ethical one. While Buchanan (2008) found in his survey that managers did not see ethical impediments to employing politics, the managers interviewed in our study appeared mindful of the ethical dilemmas posed by political engagement. The ethicality of political engagement was generally inferred based on the nature of the purpose pursued. Aligned with the outcome-oriented culture of the company, managers did not find political engagement to be objectionable when dictated by task-related imperatives. They valued 'win-win' approaches to reconciling multiple political interests. A few managers made contextual judgements about the 'wrong' and the 'right' of political action. Some of the most conflicted accounts came from women who tended to see politics mainly as the excessive pursuit of self-interest. Echoing Buchanan's findings (2008), women also appeared more concerned about the victimizing nature of politics. Both male and 
female managers were task-focused and achievement-driven, an ethic which could be described as masculine (Kanter, 1977) but also aligned with Semcom's ethos. A few female managers also spoke about an ethic of care. While some scholars have put forward normative ethical models of political behaviour (Cavanagh et al., 1981; Gotsis and Kortezi, 2009), this study surfaced some of the ethical judgements employed by managers themselves in assessing the complexities of political engagement. In order to surmise the ethicality of political engagement, all managers considered the underpinning intention as key criterion, but women were also concerned about the potential victimizing consequences. Therefore, by unearthing the (sometimes gender-specific) moral reasoning behind managerial political engagement, this study contributes to a stream of research on ethics and politics which has been predominantly normative and theoretical.

The third dimension of political will was the emotional one. Most participants described political experiences as both frustrating and rewarding, commenting how they became increasingly comfortable engaging in politics with time and experience. This is apparently at odds with Buchanan's (2008) study, suggesting that political behaviour is not a source of discomfort for managers. His study employed survey items capturing views about managers' dislike of politics in general (e.g. 'Some managers play politics for fun', 'Most managers dislike playing politics'), not about their individual subjective experiences. Our findings add insight into what exactly underpins men’s and women's (dis)comfort with politics (Arroba and James, 1988), as related to their personal engagement in it. Echoing prior studies (Davey, 2008; Mann, 1995), a few women found political engagement to be emotionally draining because political behaviours were seen as consistent with masculine norms (Alvesson, 2008), making politics a masculine enterprise, ‘a man’s thing'. Several female 
managers appeared less conflicted about this perceived incongruence between politics and their gender role, but remained mindful of how their political actions unfold in an organizational setting embedded with masculine norms. Normative gender expectations presented them with subtle constraints and opportunities. So findings suggest that the double bind (Heilman, 2001) might lead to females being disliked as political actors. In contrast and perhaps surprisingly, tokenism and engrained gender prejudice were sometimes seen to confer women an advantage in that it led men to underestimate women as political players. Overall, these findings alert us to the importance of emotion in managers' experience with politics in general, an aspect largely ignored so far. In addition, the findings suggest that political engagement was more emotionally demanding for female managers.

These three dimensions of political will were interconnected. For instance, ethical reasoning around politics was partially informed by functional beliefs. Incongruence among dimensions typically concerned the functional and emotional aspects and meant that some managers - usually female - acknowledged the functional benefits of political engagement, but were uncomfortable or unprepared to 'play the game'. Women's efforts to 'play the political game' as defined in masculine terms may be seen as ultimately reinforcing gender substructures and patterns of dominance and submission (Aker, 2002). Yet the findings suggested that political engagement can also disrupt these patterns. Interestingly, male participants were oblivious to the gendered nature of politics, illustrating how the masculine norms embedded in politics remain invisible and unquestioned (Simpson and Lewis, 2005), especially among those who benefit most from the status quo.

Mainstream approaches to organizational politics do not consider gender as a lens of analysis, thus making an implicit assumption that politics are a gender-free 
phenomenon. The findings of this study demonstrate that such an assumption is unwarranted, providing empirical evidence of gender differences in expressed political will and demonstrating that doing gender and engaging in politics are intertwined. The study also suggests that gender needs to be understood in conjuncture with organizational context and not merely as an abstract demographical variable. Using an exploratory approach, we aimed to overcome limitations of extant quantitative studies which offer a decontextualized understanding of managerial political action. The organizational setting shaped participants’ political will: while all managers embraced a task-focused and output-oriented ethos, only female managers referred to a male-dominated workforce and a masculine culture when pondering over their involvement in politics. A critical realist perspective assumes that social practices create gender orders which act as generative mechanisms - in the current study, these generative mechanisms account for gender differences in managers' expressed political will. Equally, political dynamics in the workplace shaped by the organizational ethos seemed to reinforce gender orders, thus demonstrating that generative mechanisms are dynamic and interdependent (Danermark et al., 2002).

We acknowledge several limitations of the current study and indicate opportunities for future research. First, studies in other sectors, or organizational and national settings (e.g. voluntary sector, female-dominated organizations) might yield different results in terms of how politics are construed and what underpins willingness to engage in politics for managers in general, and men and women in particular. Second, findings indicated that attitudes along the three dimensions of political will change in time, hinting at a political maturation process. This warrants further investigation into the dynamic, developmental aspects of political will and political action from a process perspective (de Ven, 2007). 
A better understanding of political will presents opportunities to put knowledge into practice, thus ensuring scholarship of consequence (Özbilgin, 2010). Unpacking political will provides insight into what drives managers to make different behavioural choices when engaging in politics. Executive training for managers could shape their political will by helping them cope with the political complexities of their roles and by encouraging constructive politics. In addition, surfacing gender aspects pertaining to politics is a first step towards deconstructing and challenging the gendered practices intertwined with politics. Efforts to develop women's political competence should aim at un-gendering politics, and not merely encouraging women to 'play the game' in a way that perpetuates structural gender inequalities.

\section{References}

Adams, G., Treadway, D. C., and Stepina, L. P. (2008). 'The role of dispositions in politics perception formation: the predictive capacity of negative and positive affectivity, equity’, Journal of Managerial Issues, 4, pp 545-563.

Acker, J. (1990). 'Hierarchies, Jobs, Bodies: A Theory of Gendered Organizations', Gender and Society, 4 (2), pp 139-158.

Alvesson, M. (1998), 'Gender Relations and Identity at Work: A Case Study of Masculinities and Femininities in an Advertising Agency’, Human Relations, 51 (8), pp 969-1005.

Arroba, T. and James, K. (1988). 'Are politics palatable to women managers? How women can make wise moves at work', Women in Management Review, 3, pp. 123130. 
Ammeter, A.P., Douglas, C., Gardner, W.L., Hochwarter, W.A. and Ferris, G.R. (2002). ‘Toward a political theory of leadership’, Leadership Quarterly, 15, pp. 433435.

Buchanan, D. (1999). 'The Logic of Political Action: An Experiment with the Epistemology of the Particular', British Journal of Management, 10 (special conference issue), pp. 73-88.

Buchanan, D. (2008). 'You Stab My Back, I’ll Stab Yours: Management Experience and Perceptions of Organization Political Behaviour', British Journal of Management, 19 (1), pp. 49-65.

Buchanan, D. and Badham, R. (2007). Power, Politics and Organizational Change: Winning the Turf Game. London: Sage.

Butcher, D. and Clarke, M. (2006). The symbiosis of organizational politics and organizational democracy, pp 286-303. In E. Vigoda-Gadot and A. Drory (ed), Handbook of Organizational Politics, MA: Edward Elgar.

Cavanagh, G. F., Moberg, D. and Velasquez, M. (1981). 'The Ethics of Organizational Politics’, Academy of Management Review, 6, pp 363-372.

Danermark, B., Ekstrom, M., Jakobsen, L., and Karlsson, J. (2002). Explaining Society: Critical realism in the social sciences, Oxon: Routlege.

Davey, M. K. (2008). ‘Women’s accounts of organizational politics as a gendering process', Gender, Work and Organization, 15, pp. 650-671.

Doldor, E. and Singh, V. (2008). ‘The Challenge of Organizational Politics: Bridging the Gap across Theoretical Domains', conference paper, American Academy of Management Conference, Anaheim, CA. 
Douglas, C. and Ammeter, A. P. (2004). 'An examination of leader political skill and its effect on ratings of leader effectiveness’, Leadership Quarterly, 15,, pp. 537-550.

Eagly, A. H. and Chaiken, S. (1993). The Psychology of Attitudes. Belmont CA: Thomson Wadsworth.

Edmondson, A.C. and McManus, S.E. (2007). 'Methodological fit in management field research’, Academy of Management Review, 32, pp. 1155-1179.

Ferris, G. R., Adams, G., Kolodinsky, R. W., Hochwater, W. A. and Ammenter, A. P. (2002). 'Perceptions of organizational politics: theory and research directions', in F. J. Yammarino, and F. Dansereau (Eds), Research in multi-level issues, volume 1. The many faces of multi-level issues, pp. 179-254. Oxford, UK: JAI Press/Elsevier.

Ferris, G. R., Treadway, D. C., Kolodinsky, R. W. and Hochwarter, W. A. 2005. 'Development and Validation of the Political Skill Inventory', Journal of Management, 31,, pp. 126-152.

Flick, U. (2009). An Introduction to Qualitative Research. London: SAGE.

Gherardi, S. (1994). 'The gender we think, the gender we do in our everyday organizational lives’, Human Relations, 47 (6), pp 591-611.

Gotsis, G. N. and Kortezi, Z. (2010). 'Ethical Considerations in Organizational Politics: Expanding the Perspective', 93, pp 497-517.

Hall, A.T., Blass, F.R., Ferris, G.R. and Massengale, R. (2004). 'Leader reputation and accountability: Implications for dysfunctional leader behaviour', Leadership Quarterly, 15, pp. 515 - 536. 
Hartley, J., Fletcher, C., Wilton, P., Woodman, P. and Ungemach, C (2007). Leading with Political Awareness: Developing leaders' skills to manage the political dimension across all sectors. London: Chartered Management Institute.

Heilman, M. E. (2001). Description and Prescription: How Gender Stereotypes Prevent Women's Ascent up the Organizational Ladder, Journal of Social Issues, $\mathbf{5 7}$ (4), pp. 657-672.

House, R. J., S. A. Shane and D. M. Herold. (1996). 'Rumors of the Death of Dispositional Research are Vastly Exaggerated." Academy of Management Review, 21, pp 203-224.

Kanter, R. M. (1977). Men and Women of the Corporation, New York: Basic Books.

King, N. (1998). Template analysis, in G. Symon and C.Cassell,. (eds.) Qualitative Methods and Analysis in Organizational Research, pp. 118-134. London: Sage.

Kumar, K. and M. Thibodeaux (1990). 'Organizational politics and planned organizational change', Group and Organizational Studies, 15 (4), pp. 357-365.

Kurchner-Hawkins, R and Miller, R. (2006). Organizational politics: Building positive political strategies in turbulent times, pp 328-353. In E. Vigoda-Gadot and A. Drory (ed), Handbook of Organizational Politics, MA: Edward Elgar.

Kvale, S. (1996). Interviews: An Introduction to Qualitative Research Interviewing, London: Sage

Lincoln, Y. S., \& Guba, E. G. (1986), But is it rigorous? Trustworthiness and authenticity in naturalistic evaluation. In D. Williams (ed.), Naturalistic Evaluation. New Directions for Evaluation, no. 30. San Francisco: Jossey-Bass. 
Madison, D. L., R. W. Allen, L. W. Porter, P. A. Renwick and B. T. Mayes (1980). 'Organizational politics: an exploration of managers' perceptions', Human Relations, 33 (2), pp 79-100.

Maio, G. R., \& Haddock, G. (2010). The psychology of attitudes and attitude change. London: Sage

Mainiero, L. A. (1994). 'On breaking the glass ceiling: The political seasoning of powerful women executives’, Organizational Dynamics, 22 (4), pp. 4-20.

Mann, S. (1995). 'Politics and power in organizations: Why women lose out', Leadership and Organization Development Journal, 16,, pp. 9-15.

Miles, M. B. and Huberman, A. M. (1994). Qualitative data analysis: An expanded sourcebook (2nd ed.). Thousand Oaks, CA: Sage.

Mintzberg, H. (1983). Power In and Around Organizations. New Jersey: PrenticeHall.

Neuman, W. L. (2006). Social Research Methods: Qualitative and Quantitative Approaches. MA: Pearson Education.

New, C. (2004). 'Sex and Gender: A Critical Realist Approach’, conference paper, Annual Conference of the International Association for Critical Realism, Cambridge, UK.

Oppenheim, A. N. (2001). Questionnaire design, interviewing and attitude measurement, (2nd ed), London: Continuum.

Özbilgin, M. F. (2010). 'Scholarship of Consequence: New Directions for the British Journal of Management', British Journal of Management, 21 (1), pp. 1-6.

Patton, M. Q. (2002). Qualitative Research and Evaluation Methods, CA: Sage. 
Pfeffer, J. (1992). Managing with power: politics and influence in organizations. Boston: Harvard Business Review Press.

Perrewe, P. L. and Nelson, D. L. (2004). 'Gender and Career Success: The Facilitative Role of Political Skill’. Organizational Dynamics, 33, pp. 366-378.

Sealy, R., Doldor, E. and Vinnicombe, S. (2009). Increasing Diversity on Public and Private Sector Boards. Government Equalities Commission, UK.

Semadar, A., Robins, G. and Ferris, G. R. (2006). 'Comparing the validity of multiple social effectiveness constructs in the prediction of managerial job performance'. Journal of Organizational Behavior, 27, pp. 443-461.

Simpson, R. and Lewis, P. (2005). 'An investigation of silence and a scrutiny of transparency: Re-examining gender in organization literature through the concepts of voice and visibility’, Human Relations, 58 (10), pp 1253-1275.

Singh, V., Kumra, S., and Vinnicombe, S. (2002). 'Gender and Impression Management: Playing the Promotion Game’, Journal of Business Ethics, 37, pp. 7789.

Ralston, D. A., Giacalone, R. A. and Terpstra, R. H. (1994). 'Ethical perceptions of organizational politics: A comparative evaluation of American and Hong Kong managers'. Journal of Business Ethics, 13, pp. 989-999.

Van de Ven, A. H. (2007). Engaged Scholarship: A Guide for Organizational and Social Research, NY: Oxford University Press.

Vinnicombe, S., Singh, V., Burke, R. J., Billimoria, D. and Huse, M. (2008). Women on Corporate Boards of Directors: International Research and Practice. Cheltenham, UK: Edward Elgar. 
Vredenburg, D H and Maurer, J G (1984). 'A process framework of organizational politics’. Human Relations. 37(1), pp 47-66.

West, C. and Zimmerman, D. H. (1987), 'Doing Gender', Gender and Society, 1 (2), pp 125-151.

White, B., Cox, C. and Cooper, C. L. (1997), 'A portrait of successful women', Women in Management Review, 12 (1), pp 27-34.

Zanzi, A. and O’Neill, R. M. (2001), 'Sanctioned versus Non-sanctioned Political Tactics’, Journal of Managerial Issues, 13, pp 245-262.

Zanzi, A., Arthur, M. B. and Shamir, B. (1991). 'The relationships between career concerns and political tactics in organizations', Journal of Organizational Behavior, 12, pp. 219-233. 